\title{
Rethinking of Self-monitoring and Self-response in Teaching Grammar Knowledge to Iranian ELT Teachers
}

\author{
Gholamreza Parvizi ${ }^{1}$, Alireza Kargar ${ }^{2}$ \\ ${ }^{1}$ Department of Foreign Languages, Alborz University, Qazvin, IR, Iran \\ ${ }^{2}$ Department of Foreign Languages, Lotestan University, Lorestan, IR, Iran \\ Correspondence: Gholamreza Parvizi, Department of Foreign Languages, Alborz University, Qazvin, IR, Iran.
}

Received: June 3, 2019

doi:10.5430/wjel.v9n2p38
Accepted: June 12, 2019 Online Published: June 14, 2019

URL: https://doi.org/10.5430/wjel.v9n2p38

\begin{abstract}
In the present days, learning and teaching researchers have emphasized the charge which teachers, tutors, and trainers' constraint knowledge treat in re-sizing and trimming what they perform in educational space. Regarding English language as a subject to teaching, although the prominence of instructor knowledge about language grammar has also been stressed, but the lack of empirical insight into the relationship between teachers' self-monitoring of grammar knowledge and self- response have been observed. With particular attention to the grammar, this article indicates and discusses information obtained from self - feedback and conversing to teachers of a kind who backwash the issue. The result of the study indicates that enabling teachers to progress and maintain a logical and realistic awareness of their knowledge about the grammar have to be prominent goal for teacher's education and development programs. Keywords: grammar knowledge, self-monitoring, self-response, teaching grammar, language teaching programs.
\end{abstract}

Keywords: self-rethinking, self-response, teaching grammar, ELT teacher

\section{Introduction}

Cognitive science is a relatively new field emerging in the mid - 1950 with the work of cognitive psychologists, linguists such as (Chomsky, N., 1957) and the establishment of artificial intelligence as a research areas. The study of cognition in language learning deals with 'mental representation and information process' and seeks to develop 'functional and neurological descriptions of the learning processes which, through exposure to representative experience, result in change, development, and the emergence of knowledge'. The usefulness of a cognitive approach to grammar instruction in ESL/EFL becomes clear when we consider the problem with purely communicative approaches. These communicative approaches tend to be based on theories which distinguish between language acquisition and learning. These theories claim but experiencing it meaningfully, as a tool for communication perhaps with target grammar structures physically highlighted or embedded within communicative activities such as task - or content - based activities as recommended by current 'focus - on - the form ' approaches to grammar instruction. This view may be acceptable for many ESL classrooms, although considerable research shows that when students receives only communicative lessons, with no instruction on grammar points, their level of accuracy suffers. However, such an approach is not useful by itself in EFL context because adequate access to communicative use of English is not usually available, and students need to develop accurate English grammar and vocabulary skills to pass exams. According to (Chastain, K., 2019) a cognitive learning has three components: 1) input, 2) information process, and 3) output. In information processing approach, the top - down and bottom - up processing are suggested to operate simultaneously to interpret incoming information. Here the individual combines new information from input with existing information stored in the long - term memory - new knowledge being developed from the interaction of input with prior knowledge. (Chastain, K., 2019) pointed out that knowledge has been divided into two general types: 1) procedural /implicit knowledge which is the knowing of how to do something and is generally unconscious, 2) declarative /explicit knowledge: is knowledge about something. It is factual information which is conscious, and is thought to consist of proposition (language - based representation) and images (perception - based representation). 


\section{Review of the Related Literatures}

\subsection{Grammar Knowledge of English Language Teachers}

The effect of teachers' knowledge of subject matter on instructional decision - making has prominent theme in research on teacher cognition. A series of studies conducted into a range of school subjects by few researchers that exploring this issue for further implications. Regarding English as particular language, the findings provided clear and concise examples of the relationship between teachers 'self - monitoring knowledge about grammar and their instructional trials. In one study, a well - developed teacher in comprehensive understanding of literature, but who was uncertain of understanding grammar, represented argumentatively different teaching behaviors during the time of giving literature and grammar lessons. In this way, (Schulman, L. S., 1986) reported those English teachers who were uncertain of their knowledge of grammar tried to avoid teaching it whenever possible. It is essential to say that teachers' lack of content knowledge can also affect the style and the form of instruction. In teaching material these teachers are uncertain of, teachers perhaps select to give lecture rather than soliciting student questions, which could guide them to unknown kingdom. In teaching grammar, for instance, one teacher raced through a review of the home work, avoiding eye contact with student the teacher might ask baffle questions. Instead of growing interest in teacher cognition (Wood, D., 1996) in the English Language Teaching literature, there has been small number of attempts to explore relationship between the teachers monitoring of their knowledge of grammar and their instructional decision. The study of relationship between teachers' metaliguistic knowledge and grammatical expounds, for instance, was not grounded in the explanations teacher gave during real classroom interaction. In terms of novelty, some researchers like (Numrich, C., 1996) and (Richards, J. C., B. HO, \& K. Giblin., 1996) reported that novice teacher avoid teaching grammar because they felt their own knowledge of grammar was indeed inadequate. But, these beliefs were never ever analyzed regarding to particular classroom sequences. Therefore, although the relationship between teachers' knowledge and classroom trial is accepted for now, our perception of how teachers' understanding of their knowledge about grammar impacts instructional decision in English Language Teaching classroom is not still strongly developed. In the rest of the paper, I attempt to present and discuss data which clarifies correspondent issue and post on further implications of the obtained data both for the teacher education program and developmental work of science.

\section{Method}

\section{Experiment}

The data collected to discuss here have come from a larger study of teacher's practices and cognition in second language grammar teaching. During this study, teachers were initially observed teaching real reasons and subsequently interviewed about their approach to grammar work. The goal of the interviews was to get insight into features which affected teachers' instructional decision on teaching grammar through a discussion of classroom's trials.

\section{Mohammad}

Mohammad is a non - native speaker of English who had been involved in TEFL for 10 years. His approach to teach grammar was strongly unplanned. He rarely walks into classroom with pre-determined grammar notions and lessons, favoring to catch on language subjects or issues which raised during the course activities, and to use a repertoire of techniques to help students think about these issues. For instance, following fluent work he would usually write down students' errors and then feed them back to class for having more discussion and self - correction, providing outlines, explanations, and trials as needed. When students asked Mohammad questions about grammar, his personal response was to give these questions back to the class with a "what is your recommendation? "Or "could you help him? ", However, there were definite classroom sequences where he did not reflect students' questions back to the class in this manner. In the example below, the students had completed a "find the object" activity, and the teacher was reviewing the types of questions they had just asked. The teacher called them for repeating the questions they had asked him for while they were trying to guess the concealed object. As the students ask questions the teacher writes the down on the board, leaving blank spaces where incorrect suggestions by student are given:

Is it used to read ........?

Where is it used to?

Is it consisted of pictures?

What is it consisted........?

The teacher asks students for the missing words in the first and the last questions. The students have no difficulties 
providing them and the teacher writes 'out' in the first question and 'of' in the last. Why is 'consisted' in the last sentence in the past?, a student asks. The teacher seems a little surprised facing such a question, and unsure about to answer the question. 'Uhh... because it is a passive voice, I guess...', he says and moves directly on with the lessons, without any further discussions or explanations of this point. Mohammad's behavior was neutral of his typical conduct in two ways. Firstly, he was visibly uneasy. Secondly, he provided direct and immediate answer to the question asked by students and moved over it without further explanations. The posts of Mohammad on this sequence are as follow:

" The reason for my uneasiness was that I did not know what the answer was, so I did not have correct response,' Because when I know the answer, my response is 'what is your recommendation?', so what happened there was ' why is it in the past?'I did not know that, and then I felt I had to produce answer. "

The relation between self - monitoring knowledge about grammar and Mohammad performance is clear here. He reflects students' question back to the class only when felt quite confident he knew the correspondent answer. But, whenever he was less confident, he over changed his characteristic behavior, in this study, by answering the question himself, not engaging with further discussion. The relation between perceived knowledge about grammar and instructional material or decision in Mohammad's work is additionally accessible. For example, when a student is asked to make clear distinction between 'let in 'and 'let off ', Mohammad responded that he needed more time to collect some tangible examples, and that he would discuss it later in a lesson. Again here, based on monitored available knowledge of the subject matter, he made a decision not to respond in his characteristic manner.

"I became aware with that one that I had had difficulty with that one before, and I have never produced anything satisfactorily for students, when he produced it, I knew through experience I needed to produce, take close look in the co - build and produce some fair examples, instead of having ineffectual time to follow."

An ultimate example of the relationship between Mohammad's monitoring knowledge about grammar and his classroom decision making extracts from a sequence in which he was helping the other students with word order of direct (e.g. ' what do you mean?') and indirect questions( e.g. 'Tell me what you mean?'). During this lesson, the instructor or teacher extracted a rule for such a sentences or phrases.

RULE ONE IF A SENTENCE STARTS WITH A QUESTION WORD, USE A QUESTION FORM, IF NOT, USE AN AFFIRMATIVE FORM.

He told the students that this is 'not 100 percent, but it is 90 percent'. I asked him for his post here: "Not enough confident to say it is the rule without exception. Therefore, I was concealing myself if they produce an example which that did not apply to, so it can be considered as a help or outline rather than a strict rule...' Consequently, one more time Mohammad's behavior was actually influenced by informative confidence he was giving the students. These data indicate Mohammad self - monitoring of his knowledge about grammar both in the form of general and particular where it refers to specific points raised during lesson sequence effects on behavioral instruction. His total confidence in his knowledge about grammar contributed to his intention to conduct regular, unplanned grammar work. It additionally stimulates him to utilize students' questions about grammar as an initiation for discussion, particular approach or strategy he avoided when he was less confident for himself. Lack of confidence also effects on his decision to protect himself with terms as qualifiers such as ' 90 percent' when he was talking about grammar knowledge.

\section{Results and Discussion}

Based on the experiment, obtained data definitely clarifies that the teacher's self - monitoring of knowledge about grammar have direct impact on his performance embedded in general and specific grammar points. Mohammad was in confident - approach mode to grammar where it was necessary, he strived to vary treatment contextually. English Language Teaching Teachers' knowledge about grammar may give effect on circles of grammar. These circles involve: the extent to which teachers teach grammar, the extent to which they intend to engage in grammatical work, the way they choose to respond to students' questions, the extent to which they progress grammatical discussion in class, the manner they reflect where their expounds are asked, and the origin or nature of the grammar they prepare for students.

Here the point is the extent to which the teacher's self-monitoring and self-response or performances have effect on his work i.e. the connection between particular behavior and level of confidence. For example the data here perhaps leads to conclude that the teachers who have more knowledge about grammar teach more grammar or teacher may bounce student's question back to the class, not because they feel confident, but they feel disable to answer those questions and need think of more to answer. The ways teachers monitor their perception clearly affect what they 
perform in class, although this may vary from teachers to teachers. Finally, the relationship between pedagogical content knowledge and teacher 'self-monitoring of subject matter is also interestingly questionable. Mohammad's confidence was accompanied by a well -developed kinds of instructional strategies for grammar work, which he applied skillfully and he had not been hindered by pedagogical content knowledge. It is also noticeable that not only knowledge about grammar but also knowledge about language (i.e. vocabulary, morphology, phonology, etc) would emerge insights on which it means it possibly impacts on student-centered approach classroom activities on language system.

A clear implication for teacher education and development, which is that work aimed at developing teacher's knowledge about language provides consistent chances to maintain realistic awareness of that knowledge, an understanding of how that awareness affect on his work. Therefore, during and after training session the teacher, in addition to enabling to develop knowledge about language, could address a) providing regular chances for ELT teachers to access current knowledge about grammar and find continuing problems while training, b) equipping ELT teachers with assessing their knowledge about grammar within their curriculum objectives and careers, c) helping ELT teachers to develop positive attitudes towards their knowledge about grammar while they are fixed, and d) making teachers well-aware that in this way self-monitoring about knowledge about grammar will impact on instructional decision. Noticing to these matters lets ELT teachers develop extended conceptualization of knowledge about grammar and its role in their performances or works. It also helps them to perceive the effect of their knowledge about grammar have on their classrooms practices.

\section{Conclusion}

There are two inclusions presented in the study: 1) teachers' self-monitoring of knowledge about grammar and what effects this have on their performances or works, and 2) developing strategies which enable ELT teachers to become well-aware of their knowledge about grammar, and understanding how this awareness affects their teaching, must be a prominent aim for those involved in their education.

\section{References}

Chastain, K. (1988). Developing Second - Language Skills, Theory and Practice. Harcourt Brace Jovanovich, USA.

Chomsky, N. (1957). Syntactic Structures. London: Mouton.

Numrich, C. (1996). On Becoming a Language Teacher: Insights from Diary Studies. TESOL Quarterly, 30(01), 131-153. https://doi.org/10.2307/3587610

Richards, J. C., B. HO, \& K. Giblin. (1996). Learning how to teach in the RSA Cert' in D. Freeman and J. C. Richards(eds.).

Schulman, L. S. (1986). Those who understand Knowledge Growth in Teaching. Educational Researcher, 15(2), 4-14. https://doi.org/10.3102/0013189X015002004

Wood, D. (1996). Teacher Cognition in Language Teaching. Cambridge University Press. 